\title{
Do mothers also "manipulate" grandparental care?
}

\author{
Mari Busch ${ }^{1}$, Sandra Olaisen ${ }^{1}$, Ina Jeanette Bruksås ${ }^{1}$, Ivar Folstad ${ }^{\text {Corresp. } 1}$ \\ ${ }^{1}$ Department of Marine and Arctic Biology, University of Tromsø, Tromsø, Norway \\ Corresponding Author: Ivar Folstad \\ Email address: ivar.folstad@uit.no
}

Paternity uncertainty has proven to be a robust ultimate hypothesis for predicting the higher investment in grandchildren observed among maternal grandparents compared to that of the paternal grandparents. Yet, the proximate mechanisms for generating such preferred biases in grandparental investment remain unclear. Here we address two different questions for better understanding the proximate mechanisms leading to the observed bias in grandparental investments: $(i)$ is there a larger emphasis on resemblance descriptions (between grandchildren and grandparent) among daughters than among sons, and (ii) do mothers really believe that their offspring more resemble their parents, i.e., the children's grandparents, than fathers do? From questioning grandparents, we find that daughters more often and more intensely than sons express opinions about resemblance between their children and their parents, i.e., about grandchild-grandparent resemblance. Moreover, daughters also seem to believe that their children more resemble their grandmother than sons do. The latter is however not the case for beliefs about children's resemblance to grandfathers. In sum, our results suggest that even in a population of Norwegians, strongly influenced by ideas concerning gender equality, there exist a sexual bias among parents in opinions and descriptions about grandparentgrandchild resemblance. This resemblance bias, which echoes that of mothers biasing resemblance descriptions of newborns to putative fathers, does not seem to represent a conscious manipulation. Yet, it could be instrumental for influencing grandparental investments. We believe that a "manipulative mother hypothesis" might parsimoniously account for many of the results relating to biased alloparenting hitherto not entirely explained by "the paternity uncertainty hypothesis". 


\section{Do mothers also "manipulate" grandparental care?}

2

3 Mari Veierud Busch, Sandra Olaisen, Ina Jeanette Bruksås and Ivar Folstad

4

5 Corresponding author Ivar Folstad

6 E-mail: ivar.folstad@uit.no

7 UiT - The Arctic University of Norway,

8 Department of Arctic and Marine Biology,

9 PO Box 6050 Langnes,

109037 Tromsø, Norway.

11

12 Running Headline: The "manipulative" mother

13

14 Keywords: Grandparental investment, resemblance, manipulation, mother, father

\section{Lay summary}

18 Parental care is a limited resource and mothers are known to communicate deceptive judgements

19 about paternal resemblance to their newborns - a behavior termed "manipulative". If

20 grandparental care is also a limited resource, conflicts may arise between siblings in need of such

21 resources. Here we examine the gender difference among sibling dyads in vocal communication

22 about their children's resemblance to their grandparents. Concurring with the manipulative

23 behavior observed among mothers, grandparents report that daughters, more than sons, more 
24 often and also more intensely voice their opinions about grandchild resemblance to them. Yet,

25 these sex difference might not result from a premeditated, conscious manipulation, as mothers,

26 more than fathers, actually seem to believe their children more resemble their parents. We

27 discuss whether the documented gender difference in communicative behavior could have

28 implications for the common, cross-cultural observation that maternal grandparents contribute

29 more resources to their grandchildren than do the paternal grandparents.

\section{Abstract}

34 Paternity uncertainty has proven to be a robust ultimate hypothesis for predicting the higher investment in grandchildren observed among maternal grandparents compared to that of the paternal grandparents. Yet, the proximate mechanisms for generating such preferred biases in grandparental investment remain unclear. Here we address two different questions for better understanding the proximate mechanisms leading to the observed bias in grandparental investments: $(i)$ is there a larger emphasis on resemblance descriptions (between grandchildren and grandparent) among daughters than among sons, and (ii) do mothers really believe that their offspring more resemble their parents, i.e., the children's grandparents, than fathers do? From questioning grandparents, we find that daughters more often and more intensely than sons express opinions about resemblance between their children and their parents, i.e., about grandchild-grandparent resemblance. Moreover, daughters also seem to believe that their children more resemble their grandmother than sons do. The latter is however not the case for beliefs about children's resemblance to grandfathers. In sum, our results suggest that even in a 
47 population of Norwegians, strongly influenced by ideas concerning gender equality, there exist a

48 sexual bias among parents in opinions and descriptions about grandparent-grandchild

49 resemblance. This resemblance bias, which echoes that of mothers biasing resemblance

50 descriptions of newborns to putative fathers, does not seem to represent a conscious

51 manipulation. Yet, it could be instrumental for influencing grandparental investments. We

52 believe that a "manipulative mother hypothesis" might parsimoniously account for many of the

53 results relating to biased alloparenting hitherto not entirely explained by "the paternity

54 uncertainty hypothesis".

55

56

571 Introduction

60 As the age of their offspring increases, parents will be favored by natural selection to switch

61 from investing in children to investing in grandchildren [1-3]. This benefit of kin altruism for

62 indirect fitness may for us (Homo sapiens sapiens) have led to an extraordinary long, and for

63 females post-reproductive, life compared to our closely related "cousins" [4, 5]. Additionally,

64 modern humans have resources easily conserved and also easily transferred between generations.

65 Yet, humans exhibit biased grandparental investment. That is, maternal grandmothers have

66 repeatedly been found to provide more care and resources to grandchildren than paternal

67 grandmothers [6-15,; see however 16]. Additionally, maternal grandfathers are found to invest

68 more in grandchildren (i.e., only second to maternal grandmothers and on the approximate same

69 level as paternal grandmothers) than paternal grandfathers, which invest the least in 
70 grandchildren [6, 9, 12, 14, 15]. Although some of the observations may be confounded [17],

71 they show, with few exceptions [16], a clear bias towards a larger grandparental investment

72 among maternal grandparents than among paternal grandparents in a diverse set of cultures.

73 Derived from evolutionary theory, the "paternity uncertainty hypothesis" [18] is the main

74 ultimate explanation for biased grandparental investment in grandchildren. Indeed, male mate

75 guarding, rather than paternal care, seems to have been the driver of the evolution of monogamy

76 in humans, as it secures a partner and ensures paternity certainty in the face of more promiscuous

77 competitors [19]. The "paternity uncertainty hypothesis" relates to the uncertainty of paternity

78 (which may be especially pronounced in species with concealed ovulation and internal

79 fertilization) the investing grandparent has to the genetic relatedness of grandchildren. Maternal

80 grandmothers can be sure of their genetic relationship to their children and grandchildren, but

81 maternal grandfathers and paternal grandparents cannot under natural circumstances be entirely

82 certain of their genetic relationship to children and grandchildren because of non-paternity (i.e.,

83 when the putative father is not biological father). There are no uncertain intergenerational

84 genetic links between a child and its maternal grandmother, one uncertain genetic link between a

85 child and its maternal grandfather and its paternal grandmother (through the child's putative

86 father), and two uncertain links between a grandchild and the paternal grandfather. Based on

87 this, the maternal grandmother is predicted to invest the most in grandchildren and the paternal

88 grandfather is predicted to invest the least. Maternal grandfathers and paternal grandmothers are

89 equally uncertain and are expected to invest more than paternal grandfathers, but less than

90 maternal grandmothers. The paternity uncertainty hypothesis has proven robust in predicting the

91 observed asymmetric grandparental investments $[6,8,9,12,14,15,20,21]$, but the proximate

92 mechanisms leading to such bias are still largely unknown. 
93 Most likely caused by the advent of modern contraceptive methods and the acceptance of

94 hygienic selective abortions, the non-paternity rates have declined from approximately 8 to $10 \%$

95 in the 1930 es to about 1 to $3 \%$ in modern industrialized western populations [22-28]. Yet, as

96 our mental concepts of non-paternity due to infidelity are not updated to the current reproductive

97 environment, subjective rates of non-paternity among males in the same modern populations are

98 as high as $10 \%[29,30]$; a number corresponding to that of non-paternity observed within present

99 hunter-gatherer societies [31]. Thus, old mental adaptions from our past evolutionary

100 reproductive environment, i.e., the environment of evolutionary adaptiveness (EEA), still evoke

101 relatively high sensitivity to possible cuckoldry and consequently non-paternity among putative

102 fathers and may similarly also influence grandparental motives. Interestingly, women in western

103 societies, who presumably should have better knowledge about female infidelity than men,

104 provide non-paternity estimates as high as $14 \%$ [29].

105 Since grandparental investment is a limited resource, grandparents that are able to separate kin

106 from non-kin would be supporting their own rather than foreign genes in future generations, and

107 consequently be favored by natural selection. One might expect that physical similarity is the

108 most useful cue for kin recognition. This has repeatedly been documented in father-offspring

109 relationships [32-36] and a positive relationship between children's resemblance to the father and

110 the father's investment in children have also been documented [32, 37-40]. Conversely, paternal

111 neglect and physical abuse have been associated with reduced resemblance between father and

112 child $[26,41,42]$.

113 As a person's own subjective experience of similarity (which originally may have been

114 established from evaluating kin) may be influenced by self-deceptive (adaptive) wishful thinking

$115[43,44]$, one should also pay attention to the opinion of others. Such opinions are often readily 
116 available, as children's resemblance to family members is often commented on [35, 45]. Yet, in

117 our verbally sophisticated species, ascriptions of resemblance by others are not entirely reliable,

118 and mothers and their relatives seem to manipulate such descriptions $[35,45,46]$. That is,

119 mothers are more likely to ascribe resemblance of newborns to the domestic father than to

120 themselves, and this bias is exaggerated in the presence of fathers and reduced in their absence

121 [45]. Moreover, objective judges match photographs of focal mothers more often to their

122 newborns than they match photographs of putative fathers to the newborns. Consequently, the

123 bias in how mothers remark resemblance clearly does not reflect actual resemblance and may be

124 an evolved or conditioned response to assure domestic fathers of their paternity [45]. It is not

125 unlikely that mothers in a similar way may also communicate deceptive judgments to

126 grandparents about grandparent-grandchild resemblance and thus influence grandparental

127 investments in grandchildren. It should be noted that such communication need not involve

128 conscious deception - it need not be premeditated.

129 Paternity uncertainty has recently been included in a larger model emphasizing parent's and 130 alloparent's benefits from investing in the mother as well as in her children [48]. That is, as

131 mothers most often are prime parental caregivers, parenting targeted towards mothers rather than 132 towards fathers gives the highest payoff in residual nepotistic value and, in turn, fitness. The 133 explanation rests on an asymmetry in fitness payoffs for parents and alloparents influencing their 134 decision making during resource allocations to mothers, fathers and their children. Although the 135 two models (i.e., paternity uncertainty and the sexual bias in residual nepotistic gains) emphasize 136 different routes to matrilateral bias in parental investments the ultimate models are not mutually 137 exclusive and may both be at work simultaneously. 
138 In the two within-family studies reported here we focus on a more proximate alternative. That is,

139 we examine how daughters and sons may differ in verbal communication of their children's

140 resemblance to grandparents. Is it possible that mothers more often and more intensely than

141 fathers communicate information about grandchildren's (i.e., their own children's) familiar

142 resemblance, not unlike that seen when mothers ascribe father's resemblance to newborns?

143 Further, if this is the case, is this difference in communication of information rooted in sexual

144 differences in beliefs about resemblance? In our first study, we asked grandparents if their sons

145 and daughters had behaved differently when ascribing grandchildren's resemblance to them. In

146 our second study, we examined whether mothers and fathers differed with regard to beliefs about

147 grandparent-grandchild resemblance. The two studies were conducted in a population exposed

148 to long-term conscience rising about gender equality and should be considered conservative.

150

151

2 Study 1

152

153 2.1 Materials and Methods

154

$155 \quad$ 2.1.1 Questionnaire

156 We constructed a questionnaire (see supplementary materials) to examine how grandparents

157 perceived their grandchildren's resemblance to them, and if they had experienced comments on

158 grandchildren's resemblance to them from their sons or daughters. The questionnaire was either

159 read as an interview between one of us (IJB or SO) and the grandparents, or sent to the

160 grandparents who filled in their answers. For simplicity, the questioning focused on the 
161 grandparent's son and daughter's firstborn child. If grandparents had more than one son or more

162 than one daughter with own children, they were asked to focus on their first son and their first

163 daughter that got children when answering the questions. They were initially asked how similar

164 they felt the two grandchildren were to them, with separate seven-point scales ranging from 1 (no

165 resemblance) to 7 (very clear resemblance) for both physical and psychological resemblance.

166 Physical resemblance was defined to the grandparents as physical characteristics like facial

167 features, body shape, posture etc., and the psychological resemblance was defined as similarity

168 in behavior, personality, talents and thought patterns. Time is a finite resource that can be

169 invested unequally among different items. Thus, one way of assessing asymmetric grandparental

170 investment is to use the reported frequency of contact between grandparents and their

171 grandchildren as a measure of investment [e.g., 14]. Contact between grandparent and

172 grandchildren was measured through questions on frequencies of face-to-face contact, as a cue

173 for their true investment of time. The grandparents were also asked whom they felt most often

174 initiated grandchildren-grandparent contact, and to give estimates of traveling distances and

175 expenses. In addition, grandparents were asked to report whether their daughter and son was

176 living with their grandchild's father or mother, respectively. Towards the end of the

177 interview/questionnaire, grandparents were asked whether their daughter, their son, or other

178 family members had ever made comments about the grandchildren's resemblance to the

179 grandparents; the nature of these comments (positive or negative regarding resemblance) and the

180 intensity with which these were made. All grandparents were Caucasian. It should also be noted

181 that Norway has a governmentally supported health care system, an average pension age of 67

182 years and a well-developed governmental child-care, including a financial support system. 
184 2.1.2 Participants

185

186 To be included in the study, respondents had to be both a maternal and paternal grandparent (i.e.,

187 they had to have at least two biological grandchildren, one through a son and one through a

188 daughter). The grandparents consented to participate after being informed that their answers

189 were to be used in a paper on resemblance and relations between grandparents and

190 grandchildren. All data collection was anonymized and ethics approval was consequently not

191 needed. 87 grandparents, 64 grandmothers and 23 grandfathers, with no relation to each other,

192 answered the questionnaire (one did not report on resemblance descriptions). Most of the

193 respondents were sampled haphazardly from various public locations in Northern Norway, such

194 as the University Hospital of North Norway and shopping malls in the towns Tromsø and

195 Narvik. Some respondents were also recruited through family and friends in Narvik, Lofoten,

196 Mosjøen, Sortland and Steigen. The mean age of grandparents was 65 years (range: 54-89; eight

197 grandparents did not report their age). The average age was 45 years for both their first

198 daughters to have children (range 25 - 62), and for their first sons to have children (range 28 -

199 64). For the firstborn child of the respondents' daughters, the mean age was 20 years (range, 6

200 months - 44 years), where 37 of them were boys, and 50 girls. For the son's firstborn child, the

201 mean age was 17 (range, 6 months - 40 years), of which 43 of them were boys, and 46 were girls.

202 Although our hypothesis gives clear predictions about the directions of the outcome for the male-

203 female comparisons, P-values are reported two-tailed throughout. Yet, we have not adjusted for

204 multiple comparisons $[49,50]$.

205

206 2.2 Results 
208 There was no sex difference in the age of parents $\left(\mathrm{F}_{172}=0.28, \mathrm{P}=0.82\right)$ or in the age of their

209 firstborn child $\left(\mathrm{F}_{168}=0.46, \mathrm{P}=0.10\right)$. Moreover, the traveling distance (given as duration of

210 travel) to the firstborn of daughters was reported by $44 \%$ of the respondents to be less than 30

211 minutes, between 30 minutes and 4 hours for 23\%, and more than 4 hours for the remaining

$21233 \%$. For the firstborn of sons, the traveling distance was less than 30 minutes for $44 \%, 30$

213 minutes to 4 hours for $11 \%$, and more than 4 hours for $45 \%$ of the grandparents. There was no

214 significant difference in traveling distance to daughter's or son's firstborn $\left(\chi^{2}=4.80, p=0.09\right)$.

$21566 \%$ of the grandparents estimated a cost of 500 Norwegian Kroners (NOK) or less in traveling 216 expenses for reaching their daughters' firstborn, whereas 9\% estimated a cost between 500 and $2171500 \mathrm{NOK}$, and 25\% estimated more than 1500 NOK. For their sons' firstborn, 56\% estimated a 218 cost less than 500 NOK, 15\% between 500 and 1500 NOK, and 29\% more than 1500 NOK. No 219 significant difference was found in traveling expenses to son's or daughter's firstborn child $\left(\chi^{2}=\right.$ $2201.98, \mathrm{p}=0.37)$

221

222 More grandparents reported having more frequent face-to-face contact with their daughter's 223 child than their son's child (daily or weekly: $45 \%$ vs. $29 \%$; monthly to every sixth month: $46 \%$ 224 vs. $61 \%$; once a year or less: $9 \%$ vs. $10 \%$, respectively). That is, in the role as maternal 225 grandparents, grandparents have slightly more frequent contact with their grandchildren than in 226 the role as paternal grandparents. Although this does indicate behavioral differences between 227 maternal and paternal grandparents, no strict statistical differences in contact frequencies could 228 be documented $\left(\chi^{2}=4.94, \mathrm{p}=0.08\right)$. For visits to their daughter's child, $22 \%$ of the 229 grandparents said they were most often the initiator of visits, whereas $39 \%$ said their grandchild 
230 initiated visits. Moreover, $30 \%$ of the grandparents said the visits were initiated equally, and the

231 remaining 4\% were not sure. For visits to their son's child, $25 \%$ of the grandparents said they

232 most frequently initiated the visits, 38\% answered their grandchild did, 33\% said both and 3\%

233 were not sure. That is, differences in grandparental initiations of visits to the daughters' and the

234 sons' child was not significant $\left(\chi^{2}=0.39, \mathrm{p}=0.94\right)$. Additionally, more daughters than sons

235 were reported by the grandparents to live together with their child's parent (75\% vs. 63\%), but

236 the difference was not significant $\left(\chi^{2}=2.03, \mathrm{p}=0.15\right)$.

238 Grandparents reported their daughter's child to resemble them slightly more than their son's

239 child for both physical and psychological resemblance. That is, mean rating for physical

240 resemblance between grandparent and the child of a daughter was $3.4(\mathrm{SD}=1.7)$, while mean

241 rating for the son's child's resemblance to the grandparent was $3.0(\mathrm{SD}=1.7)$. This difference

242 was not significant $\left(\chi^{2}=5.45, \mathrm{p}=0.49\right)$. The respective values for psychological resemblance

243 was $4.0(\mathrm{SD}=1.6$, for the daughter's child $), 3.5(\mathrm{SD}=1.6$, for the son's child $)$ and $\chi^{2}=5.61, \mathrm{p}=$

244 0.47. However, when grandparents were asked in a force choice manner whether their son's or

245 their daughter's child resembled them the most, the results were in favor of the child of their

246 daughter, both for physical $\left(\chi^{2}=10.6, \mathrm{p}=0.001, \mathrm{n}=48\right.$ daughters' child, $\mathrm{n}=21$ sons' child $)$ and

247 psychological resemblance $\left(\chi^{2}=5.71, \mathrm{p}=0.02, \mathrm{n}=45\right.$ daughters' child, $\mathrm{n}=25$ sons' child $)$.

249 When asked if any family members had mentioned anything about their grandchildren's

250 resemblance to them, 59\% $(\mathrm{n}=49)$ of the grandparents confirmed this. Sisters, brothers, uncles,

251 aunts, great grandmothers, and in-laws were the ones who had made comments on grandchild-

252 grandparent resemblance. $49 \%(n=24)$ of the comments had been made about the daughter's 
253 child, and 51\% $(\mathrm{n}=25)$ about the son's child. However, when asked whether they could recall

254 their son or daughter ever emphasizing their own child's resemblance to them, the results were 255 quite different. Of the $42 \%$ of the grandparents who remembered that their children had talked 256 about resemblance, $33 \%$ of them reported that only their daughter had mentioned the topic, while $25710 \%$ of them reported their son to be the only one to have made comments on resemblance 258 (exact binomial test, $\mathrm{p}=0.03, \mathrm{n}=4$ sons, $\mathrm{n}=14$ daughters, Figure 1 ). When only including 259 grandfather's recollection about who made comments, the difference was still apparent $\left(\chi^{2}=5, p\right.$ $260=0.03, \mathrm{n}=5$ daughters and 0 sons).

261

262

- figure 1 approximately here -

263

264 The remaining $57 \%$ of the grandparents, who remembered their children emphasizing 265 resemblance, reported that both their son and daughter had made such comments. These 266 grandparents were asked whom they felt most frequently or insistently made such comments. $26754 \%$ said their daughter, 38\% said they could not recall any difference in neither frequency or 268 intensity, and only $8 \%$ said their son was more insistent (exact binomial test, $\mathrm{p}=0.007, \mathrm{n}=2$

269 sons, $n=13$ daughters, Figure 2). Thus, daughters significantly more often than sons, 270 intensively reminded their parents about their child's resemblance to them.

- figure 2 approximately here -

273

274 Grandparents were also asked whether their son or daughter had ever stated that their siblings' 275 child did not resemble them, and as many of $93 \%$ of them could not recall any of them 
276 mentioning this. Of the remaining grandparents, $3 \%$ had experienced only their daughter making

277 such comments, $1 \%$ only their son and $2 \%$ had heard comments from both of them. No

278 meaningful difference was found for these results (exact binomial test, $\mathrm{p}=0.63, \mathrm{n}=1$ son, $\mathrm{n}=3$

279 daughters).

280

281

282

283

3. Study 2

284

285

3.1. Materials and Methods

286

287

\subsubsection{Questionnaire}

288 We constructed a questionnaire (see supplementary material) to examine parents' perceived 289 resemblance to and between close kin. In this study, close kin are children, parents, siblings 290 (restricted to the first four), nieces and nephews. All parents were asked to categorize the term 291 resemblance as resemblance in personality (i.e., psychological) or in appearance (i.e., physical)

292 before answering the questions concerning resemblance to and between kin. This is because the 293 term resemblance does not necessarily make a distinction between the two, and psychological 294 and physical resemblance might weigh differently for investment decisions made by males and 295 females. That is, fathers may be more influenced by physical resemblance and less influenced 296 by psychological resemblance than mothers [51]. Parents were further asked to give the age and 297 sex of their child/children and sibling/siblings. In addition, they were told to estimate, on a 298 seven-point scale ranging from 1 (< yearly) to 7 (daily), their child/children's current frequency 
299 of contact with their mother and father (i.e., respondent's parents), respectively. In the second

300 half of the interview, questions were asked in a forced choice manner. Parents were asked to

301 answer which one's children they thought resembled the respondent's own mother and father the

302 most, their own children or their sister's/brother's children. In a similar manner, parents were

303 asked whether they saw their child/children as resembling them more or less then their sibling's

304 children resembling their sibling. Respondents having more than one sibling of the same and/or

305 opposite sex, which also had children, were instructed to make the comparisons to the sibling

306 closest in age.

307

308

\subsubsection{Participants}

309 Males and females of the scientific staff, all with Scandinavian sounding first and surnames, at

310 various faculties at the University of Tromsø, were opportunistically contacted on their office

311 telephones during working hours by one of the authors (MVB). The potential respondents were

312 informed that the authors were writing a paper on family resemblance, after which they were

313 asked to participate in a telephone interview on the subject. In order to make the sampling as

314 random as possible, no information about the staff, other than name (i.e., sex), office telephone

315 number and position at the University, was known prior to contact. 51 consenting participants

316 (21 males and 30 females; mean age $\pm \mathrm{SD}=50.26 \pm 10.85,50.23 \pm 7.98$ ) met the criteria of

317 having at least one biological child and one sibling of the opposite sex also with at least one

318 biological child. The average age of firstborns among female parents was 20.7 years $(\mathrm{SD}=9.5)$

319 and 17.7 years $(\mathrm{SD}=2.7)$ among male parents. All data were anonymized and, according to the

320 Norwegian Data Protection Office for Research (NSD), no ethical approval was needed. Male

321 participants had a mean $\pm \mathrm{SD}$ of sons $=0.91 \pm 0.89$, and daughters $=1.14 \pm 0.62$. Female 
322 participants had $1.1 \pm 0.96$ sons, and $1.1 \pm 0.85$ daughters. The respondents were asked to

323 estimate the current frequency of contact between their children and the respondent's parents.

324 This required that the grandparents in question were still alive, which was not the case for all

325 respondents. Due to this and because not all participants had a sibling of the same sex or were

326 able to answer every question, the sample size varies for the different analyses and will be given

327 for each. Again, P-values are reported two-tailed.

328

329

330

3.2. Results Study 2

331 There was no sex difference in the age of the respondent's children $\left(\mathrm{F}_{49}=3.3, \mathrm{P}=0.33\right)$.

332 Moreover, mothers and fathers in this sample did not differ in categorizing resemblance to

333 resemblance in personality, appearance, or both $\left(\chi^{2}=0.02, \mathrm{df}=2, \mathrm{p}=0.99\right) .13(61.9 \%)$ males

334 and $19(63.3 \%)$ females reported that they found resemblance in both personality and appearance

335 to be equally important when assessing resemblance. Only $2(9.5 \%)$ males and $3(10.0 \%)$

336 females stated that resemblance in appearance was most important, and $6(28.6 \%)$ males and 8

$337(26.7 \%)$ females found resemblance in personality as most important in assessment of 338 resemblance.

339

340 Females had a tendency to report their children's contact with the children's maternal

341 grandmother as more frequent than what was reported by males regarding their children's

342 contact with paternal grandmother $(\mathrm{t}=-1.35, \mathrm{df}=32, \mathrm{p}=0.19, \mathrm{n}=15$ males and $\mathrm{n}=19$

343 females). The frequency of contact between children and the respondent's father was not 
344 differently reported by males and females $(t=0.74, d f=19, p=0.47, n=7$ males and $n=14$ 345 females).

346

347 When asked whose children resemble the respondent's mother the most, the respondent's 348 children or the children of an opposite sexed sibling, females reported greater resemblance

349 between their own children and their mother (the children's maternal grandmother) compared to 350 what males did (reporting resemblance to the children's paternal grandmother) (Figure 3). The 351 reversed pattern, though not significant, was found when the respondents were asked to assess 352 their children's resemblance to grandmother relative to the children of a sibling of the same sex $353\left(\chi^{2}=1.6, p=0.21, \mathrm{n}=24\right)$. That is, both males and females reported own children to bear more 354 resemblance to the children's grandmother (the respondent's mother) compared to a brother's 355 children, but not when compared to a sister's children.

356

357

358

- figure 3 approximately here -

359

360

361 When reporting resemblance between children and the children's grandfather (the respondent's

362 father), there was no difference between males and females, neither when comparing own

363 children to the children of a sibling of the opposite sex $\left(\chi^{2}=0.11, p=0.74, n=46\right)$, nor when

364 comparing own children to the children of a sibling of the same $\operatorname{sex}\left(\chi^{2}=0.33, p=0.57, n=19\right)$.

365 Both males and females, though, stated that their children were more similar to their father (the 366 grandchildren's paternal and maternal grandfather, respectively) than a sibling's children are, 
367 irrespective of the siblings' sex. For resemblance to the children's grandfather, 17 out of $26\left(\chi^{2}\right.$ $368=2.77, \mathrm{p}=0.10$ ) females stated that their children resembled their grandfather more than their 369 brother's children did, and 14 out of $20\left(\chi^{2}=2.77, \mathrm{p}=0.10\right)$ males reported the same for their 370 children's resemblance to grandfather when compared to a sister's children. These results are

371 comparable to the answers given by the respondents when asked which one of themselves and

372 their sibling share most resemblance with their children. Most males and females stated that

373 there was more resemblance between themselves and their own child (children) than between an 374 opposite sexed sibling and his/her child (children) (for females: 20 vs. 4 in favor of own 375 resemblance; for males: 12 vs. 7 in favor of own resemblance). 


\section{4. Discussion}

380 Our materials and methods

381 Females are overrepresented in our samples of both parents and grandparents. Yet, as mothers 382 and fathers do not differ in categorizing the term resemblance, answers given to the questions 383 concerning resemblance in the present study seem to reflect similar modes of underlying 384 evaluations for male and female respondents. Moreover, while it might be argued that such 385 resemblance assessment between generations could be confusing for the respondents, the 386 questions in the present two questionnairs were constructed in such a way that the respondent 387 made only a single comparison for each question. It is therefore likely that the recorded answers 388 reveal the respondents' opinions. Yet, whether and to what extent these opinions are constrained 389 by cultural correctness or evolved mental constructs is difficult to assess. The many

390 observations of no sexual difference throughout both studies, followed by a sudden appearance 391 of sexual difference only under forced choice questioning might, however, hint to an influence of 392 cultural correctness over self-reported opinions. Moreover, the reluctance to participating and 393 answering some of the questions (own observations) adds to the latter.

395 Our results

396 Although both sons and daughters potentially could benefit from emphasizing resemblance 397 between grandparents and own offspring [52], daughters more than sons seem to voice opinions 398 about grandparent-grandchild resemblance in our sample. Daughters also voice opinions more 399 intensely than sons do. Additionally, mothers, more than fathers, seem to believe that their 
400 children resemble their mother - the child's maternal grandmother and prime grandparental

401 investor $[9,15]$. The latter sex-difference in resemblance opinions is however not evident for

402 descriptions of grandfather-grandchild resemblance.

403

404 Although belief in genetic relatedness has been found to affect resemblance ratings in a positive 405 direction [34, 53], it could be argued that an increased contact rate and intimacy between 406 maternal grandparents and grandchildren could lead daughters to report a larger resemblance

407 between their children and their familiar grandparents than sons do. Under this scenario, 408 increased contact leads to a sense of increased resemblance due to familiarity rather than vice 409 versa. Yet, although our present questioning of parents and grandparents suggest that 410 grandparents may have a slightly higher frequency of contact with daughters' children than with 411 sons' children, and that grandparents may also show small differences in initiating contact with 412 daughter's rather than son's children, none of these differences reach statistical significance.

413 Additionally, grandparents do not live closer to their daughters than to their sons, and there seem 414 not to be differences in expenses for travels to sons or daughters. In our sample of grandparents, 415 there is also no difference between sons and daughters in whether they still live with the 416 grandchild's biological parent. That is, given equal opportunity for cohabitation with biological 417 children, sons and daughters would experience similar time-periods when children live with a 418 biological parent that is not the child of the focal grandparent. Moreover, there is no systematic 419 age-bias in our sample, suggesting a longer exposure time to grandchildren of daughters rather 420 than sons. In sum, this suggests that opportunities for grandparental contact with grandchildren

421 in our sample are not more constrained for children of sons than for children of daughters.

422 Additionally, when questioning parents about contact rates between their children and their 
423 grandparents, we find no significant sex differences. Although many of the comparisons listed

424 above show a slightly larger potential for contact between maternal than paternal grandparents,

425 none of them alone reach effect sizes comparable to those found for sexual differences in

426 parental resemblance descriptions. That is, compared to the measured differences in indices of

427 intimacy reported in our samples (i.e., grandparent reported contact rate, their initiations of

428 contact, settlement distance between grandparent and parent, cohabitation of parents and parental

429 reported grandparent-grandchild contact), there are large sex-differences in grandparental

430 descriptions and opinions on resemblance. This suggests that the reported resemblance bias may

431 partly be established independent of differences in contact rates. Still, it cannot be excluded that

432 the effects of a slightly larger potential for contact between maternal grandparents and

433 grandchildren could be causing the sexual difference in parental descriptions and opinions

434 reported by grandparents. In that case, one would suspect that resemblance descriptions were

435 reflected in the response from grandparents. The unconstrained response from grandparents does

436 not suggest that grandparents felt any resemblance bias towards daughter's children over son's

437 children, that is, grandparents did not report that daughter's firstborn resembled them

438 psychologically or physically more than son's firstborn. Still, when constrained, and force-

439 choice questioned about whether grandparents felt their son's or their daughter's child resembled

440 them the most, the results were definitely in favor of the child of their daughter. We believe that

441 the constriction under our questioning lead the respondents to deviate from their default

442 politically "correct" response, to reporting their "real" opinion. In sum, the presence of our

443 documented sex-specific bias in resemblance-beliefs is interesting independent of the causal

444 pathway for its establishment (i.e., whether it is nurture or nature), as it might both cause and

445 reinforce asymmetric investment decisions by all four grandparents. 
447 Grandparents reported that daughters more often than sons talked about grandchildren's

448 resemblance. Additionally, when both their daughter and son had made comments about the

449 subject, the daughter was described as the most intensive, making comments more frequently

450 than her brother. Most of the participants in this survey were grandmothers (74\%), so these

451 findings are not surprising considering that the subject might be considered "girl-talk material".

452 Daughters could therefore be expected to talk more about resemblance to their mothers than sons

453 do. However, using only the grandfather's reported answers, the difference was still significant

454 in "favor" of the daughters. Thus, these results are better explained by the potential influence of

455 differences in beliefs held and reported by mothers and fathers. Our present results also

456 correspond closely with results from a study of 177 female and 56 male Norwegians, having

457 siblings of the opposite sex with children. In this study, where subjects where recruited among

458 parents with kids in kinder-gardens, both males and females reported that sisters more often and

459 more intensely commented on resemblance of own and others children than brothers [54].

460 Clearly, resemblance descriptions are not "girl-talk material" only. Our finding of a larger

461 emphasis on resemblance descriptions among daughters than sons observed by both grandfathers

462 and grandmothers correspond with the documented sexual differences in resemblance beliefs,

463 and it also clearly echoes results from studies documenting that mothers are more likely to

464 emphasize their newborn's resemblance to the putative father when he is present, than when

465 absent $[32,45]$. Although the latter results only apply to putative fathers, it cannot be excluded

466 that the underlying mental modules may also be operating in relation to grandparental

467 resemblance descriptions. 
469 The larger perspective

470 Several studies have indicated that males, due to paternity uncertainty, should rely more heavily

471 on resemblance to children, as a cue of genetic relatedness, for investment decisions than females

472 [e.g., 35, 38-41, 45, 51, 55], but few have extended and investigated this prediction regarding

473 grandparental investment (see however $[9,52,56]$. Also, putative relatedness weighted by

474 certainty in relatedness, better predict willingness to invest in kin than putative relatedness alone

475 [57], and kin selection theory is also supported by studies comparing investments by

476 grandparents and step-grandparents $[58,59]$. In fitness terms, grandparental investments can be

477 viewed as an extension of parental investment, or as Euler and Weitzel [9] points out, as a

478 "differentiated subset of parental effort". Consequently, investment decisions made by

479 grandparents should be subjected to the same scrutiny as paternal investment decisions.

480 Assuming that grandparents are sensitive both to the belief in genetic relatedness and influenced

481 by what others tell them regarding resemblance to kin, it is not unlikely that their children can

482 influence their investment decisions. Females, who are known to bias resemblance descriptions

483 in their favor $[32,45]$, may indirectly raise doubt about a brother's paternity by emphasizing

484 both their own resemblance and their mother's resemblance to their children. This could, in turn,

485 affect their mother's investment decisions and explain why maternal grandmothers repeatedly

486 appear as the prime grandparental caregivers. It is, however, important to emphasize that this

487 sexual difference in belief and vocal behavior does not have to involve conscious manipulation.

488 It need not be premediated, but rather an evolved unconscious response. Additionally, mothers

489 could also influence their children and it is, in this perspective, interesting that grandchildren are

490 found to rate their resemblance to maternal grandmothers as higher than to maternal grandfathers

491 [9]. The alternative approach to resemblance descriptions, i.e., to increase dissimilarity 
492 descriptions of a sibling's children, seem to be less prevalent in our present sample (see also

493 [54]), maybe because dissimilarity descriptions may be considered un-polite, and consequently

494 carry costs to the signaler. Moreover, reporting such behavior might also be less acceptable -

495 especially among Norwegians.

496

497 Although there might certainly exist cultural effects on decision making among all parents, our

498 "manipulative mother hypothesis" (i.e., that mothers mentally exploit the alloparenting

499 environment by expressing biased resemblance descriptions) could explain many of the results

500 not entirely predicted by the "paternity uncertainty hypothesis" alone (see [60]). For example,

501 the higher grandparental investments observed among maternal grandfathers compared to that of

502 the equally uncertain paternal grandmothers (e.g., [9]), the larger caregiving towards nieces and

503 nephews observed among maternal aunts compared to that of paternal aunts [15] and the

504 maintenance of a high matrilateral caregiving among orthodox Jews under high paternity

505 certainty [61] are all results that correspond to a larger manipulation of the alloparenting

506 environment among mothers than fathers. Even among rural Greeks, where a patrilateral bias in

507 caregiving is present with the paternal grandmother as the largest investor [21], one cannot

508 exclude that maternal manipulation can be at work. Yet, all except the latter of these results

509 could also be explained if alloparental investments for increased residual nepotistic value of

510 mothers gives larger fitness benefits to grandparents than similar investments in fathers [48].

511 Our more parsimonious model, which does not rest upon the above assumption, could account

512 for all the above findings. Additionally, the "manipulative mother hypothesis" might throw new

513 light on why parenthood improves emotional closeness and contact rate between daughter and

514 mother $[62,63]$, on why emotional closeness and intimacy between sons and mothers decrease 
515 after the birth of their first child [62] and, not least, on why the relationship between daughter-in-

516 law and mother-in-law has repeatedly been reported to be the least healthy of all parent-

517 grandparent relationships [64-67] and thus of potential importance for grandparental support

518 [13]. Our hypothesis rests firmly on the repeated findings of deceitful verbal assurance given by

519 mothers to putative fathers [32, 35, 45], and future Functional Magnetic Resonance Imaging

520 evaluations could be able to examine whether the same cognitive process domains are involved

521 in both "manipulative" actions. In a larger picture, it also conforms to the slight tendency

522 towards a larger use of indirect aggression, e.g., gossiping, among females compared to males

$523[68,69]$ and to the repeatedly observed, and sometimes quite large negative effects from

524 reproductive competition among human females [70-73] - even within kin groups [74-77]. In

525 sum, the "manipulative mother hypothesis" alone, or in some combination with the "paternal

526 uncertainty hypothesis" and the Perry and Daly (2017) model, might account for many of the

527 results that hitherto have been hard to explain parsimoniously. The hypothesis gives clear

528 predictions (e.g., when mothers have restricted access to the alloparenting environment the

529 biased alloparenting should be reduced), and it could consequently easily be falsified.

530

\section{5. Conclusion}

532

533 This study is limited to only include a sample of academics and grandparents from various

534 locations in North-Norway. Yet, as Norwegians in general, and in particular Norwegian

535 academics, have been exposed to conscience rising about gender equality, these results should be

536 considered conservative. It is thus plausible that the grandparent's higher perceived resemblance

537 to their daughter's children, daughter's stronger beliefs about children's resemblance to their 
538 mother, and the daughters larger extent of resemblance descriptions is not unique for

539 grandparents and parents from Norway. Additionally, the findings may provide a mechanistic,

540 proximate explanation for asymmetric grandparental investment where paternal grandparents are

541 usually found to invest less in grandchildren than maternal grandparents - especially the

542 maternal grandmother. Our study, as any one study, is in no way exhaustive, and whether our

543 findings will stand the scrutiny of future meta-analysis on lager data, remains to be evaluated.

544 Yet, we hope our ideas might inspire researchers to explore previously unimagined avenues.

545

\section{6. Acknowledgements}

547

548 Our model is controversial and has been difficult to publish. Therefore, a great thanks to the

549 editor for allowing us to present our contribution and to the two reviewers (the anonymous and

550 Denson McLain) for constructive critics and excellent ideas. Thanks also to Ivar's sister and

551 mother of own kids who initiated these investigations by stating, in the presence of their mother:

552 “Ivar, your kids don’t look like you". Thanks also to Joakim Carlsen, Hella Veierud Busch,

553 Marit Folstad, Bill Olaisen and Helen Thoresen for encouragements, to Alexander Pashos for his

554 advice in the planning phase of parts of the study, to Harald A. Euler for reading through an

555 earlier draft of the manuscript and for his constructive feedback and to Ole Petter Laksforsmo

556 Vinstad for discussions and linguistic improvements at a late stage. Although it is impossible for

557 us to thank those of the scientific staff at various faculties at the University of Tromsø and

558 grandparents in different parts of Northern Norway for participating in the survey, we hope our

559 small return (a lottery ticket) gave some pleasure. 
561

PeerJ reviewing PDF | (2018:08:30207:1:1:NEW 10 Oct 2018) 


\section{Uncategorized References}

564 1. Hawkes K, O'Connell JF, Jones NGB, Alvarez H, Charnov EL. Grandmothering,

565 menopause, and the evolution of human life histories. Proceedings of the National Academy 566 of Sciences of the United States of America. 1998;95:1336-9. doi: 10.1073/pnas.95.3.1336. 567 PubMed PMID: ISI:000071878500095.

568 2. Mace R. Evolutionary ecology of human life history. Anim Behav. 2000;59:1-10. doi: 569 10.1006/anbe.1999.1287. PubMed PMID: WOS:000085872900001.

570 3. Croft DP, Brent LJN, Franks DW, Cant MA. The evolution of prolonged life after

571 reproduction. Trends in Ecology \& Evolution. 2015;30(7):407-16. doi:

572 10.1016/j.tree.2015.04.011. PubMed PMID: WOS:000357755500012.

573 4. Hamilton WD. The moulding of senescence by natural selection. Journal of

574 Theoretical Biology. 1966;12(1):12-45. doi: http://dx.doi.org/10.1016/0022-

575 5193(66)90184-6.

576 5. Williams GC. PLEIOTROPY, NATURAL-SELECTION, AND THE EVOLUTION OF

577 SENESCENCE. Evolution. 1957;11(4):398-411. doi: 10.2307/2406060. PubMed PMID:

578 WOS:A1957XE15100002.

5796 6ishop DI, Meyer BC, Schmidt TM, Gray BR. Differential investment behavior

580 between grandparents and grandchildren: The role of paternity uncertainty. Evolutionary

581 Psychology. 2009;7:66-77. PubMed PMID: ISI:000266638400009.

582 7. Busch MV. Asymmetries in perception of kin resemblance in relation to paternity

583 uncertainty. MScThesis, University of Tromsø. 2010.

584 8. Danielsbacka M, Tanskanen AO, Jokela M, Rotkirch A. Grandparental Child Care in

585 Europe: Evidence for Preferential Investment in More Certain Kin. Evolutionary

586 Psychology. 2011;9(1):3-24. PubMed PMID: WOS:000287850800001.

587 9. Euler HA, Weitzel B. Discriminative grandparental solicitude as reproductive

588 strategy. Human Nature-an Interdisciplinary Biosocial Perspective. 1996;7:39-59. PubMed

589 PMID: ISI:A1996TW81700002; PubMed Central PMCID: PMC1996.

590 10. Fischer LR. Transition to grandmotherhood. International Journal of Aging \& Human

591 Development. 1983;16:67-78. doi: 10.2190/GU3R-506F-2UMW-6L8R. PubMed PMID:

592 ISI:A1983QJ60000006.

593 11. Gibson MA, Mace R. Helpful grandmothers in rural Ethiopia: A study of the effect of 594 kin on child survival and growth. Evolution and Human Behavior. 2005;26:469-82. doi:

595 10.1016/j.evolhumbehav.2005.03.004. PubMed PMID: ISI:000233186000003.

596 12. Laham SM, Gonsalkorale K, von Hippel W. Darwinian grandparenting: Preferential 597 investment in more certain kin. Personality and Social Psychology Bulletin. 2005;31:63-72. 598 doi: 10.1177/0146167204271318. PubMed PMID: ISI:000225675900005.

599 13. Michalski RL, Shackelford TK. Grandparental investment as a function of relational 600 uncertainty and emotional closeness with parents. Human Nature-an Interdisciplinary 601 Biosocial Perspective. 2005;16:293-305. doi: 10.1007/s12110-005-1012-5. PubMed PMID: 602 ISI:000232952900004.

603 14. Pollet TV, Nelissen M, Nettle D. Lineage based differences in grandparental 604 investment: Evidence from a large British cohort study. Journal of Biosocial Science.

605 2009;41:355-79. doi: 10.1017/s0021932009003307. PubMed PMID:

606 ISI:000265319800004. 
607 15. Pashos A, McBurney DH. Kin relationships and the caregiving biases of

608 grandparents, aunts, and uncles - A two-generational questionnaire study. Human Nature-

609 an Interdisciplinary Biosocial Perspective. 2008;19:311-30. doi: 10.1007/s12110-008-

610 9046-0. PubMed PMID: ISI:000258530000008.

611 16. Pashos A. Does paternal uncertainty explain discriminative grandparental

612 solicitude? A cross-cultural study in Greece and Germany. Evolution and Human Behavior.

613 2000;21(2):97-109. doi: 10.1016/s1090-5138(99)00030-6. PubMed PMID:

614 WOS:000086726900003.

615 17. Tran US, Fisher ML, Voracek M. Spousal Age Differences and Sex Differences in Life 616 Expectancy are Confounders of Matrilateral Biases in Kin Investment. Basic and Applied

617 Social Psychology. 2009;31(4):295-303. doi: 10.1080/01973530903316773. PubMed

618 PMID: WOS:000274301800003.

619 18. Smith MS. Research in developmental sociobiology: Parenting and family behavior.

620 In: MacDonald KB, editor. Sociobiological perspectives on human development. New York:

621 NY: Springer; 1988. p. 271-92.

622 19. Schacht R, Bell AV. The evolution of monogamy in response to partner scarcity.

623 Scientific Reports. 2016;6. doi: 10.1038/srep32472. PubMed PMID:

624 WOS:000382706600001.

625 20. Danielsbacka M, Tanskanen AO. Adolescent grandchildren's perceptions of

626 grandparents' involvement in UK: an interpretation from life course and evolutionary

627 theory perspective. European Journal of Ageing. 2012;9(4):329-41. doi: 10.1007/s10433-

628 012-0240-x. PubMed PMID: WOS:000310318500006.

629 21. Pashos A. Does paternal uncertainty explain discriminative grandparental

630 solicitude? A cross-cultural study in Greece and Germany. Evolution and Human Behavior.

631 2000;21:97-109. doi: 10.1016/S1090-5138(99)00030-6. PubMed PMID:

632 ISI:000086726900003.

633 22. Anderson KG. How well does paternity confidence match actual paternity? Evidence

634 from worldwide nonpaternity rates. Current Anthropology. 2006;47:513-20. doi:

635 10.1086/504167. PubMed PMID: ISI:000239041100006.

636 23. Larmuseau MHD, Vanoverbeke J, Van Geystelen A, Defraene G, Vanderheyden N,

637 Matthys K, et al. Low historical rates of cuckoldry in a Western European human

638 population traced by Y-chromosome and genealogical data. Proceedings of the Royal

639 Society B-Biological Sciences. 2013;280(1772). doi: 10.1098/rspb.2013.2400. PubMed

640 PMID: WOS:000330325400024.

641 24. Voracek M, Haubner T, Fisher ML. Recent decline in nonpaternity rates: A cross-

642 temporal meta-analysis. Psychological Reports. 2008;103:799-811. doi:

643 10.2466/pr0.103.3.799-811. PubMed PMID: ISI:000263347200023.

644 25. Wolf M, Musch J, Enczmann J, Fischer J. Estimating the Prevalence of Nonpaternity in

645 Germany. Human Nature-an Interdisciplinary Biosocial Perspective. 2012;23(2):208-17.

646 doi: 10.1007/s12110-012-9143-y. PubMed PMID: WOS:000305912800005.

647 26. Bellis MA, Hughes K, Hughes S, Ashton JR. Measuring paternal discrepancy and its

648 public health consequences. Journal of Epidemiology and Community Health.

649 2005;59(9):749-54. doi: 10.1136/jech.2005.036517. PubMed PMID:

650 WOS:000231209100011.

651 27. Larmuseau MHD, Claerhout S, Gruyters L, Nivelle K, Vandenbosch M, Peeters A, et al.

652 Genetic-genealogy approach reveals low rate of extrapair paternity in historical Dutch 
653 populations. American Journal of Human Biology. 2017;29(6). doi: 10.1002/ajhb.23046.

654 PubMed PMID: WOS:000415199300015.

655 28. Larmuseau MHD, Matthijs K, Wenseleers T. Cuckolded Fathers Rare in Human

656 Populations. Trends in Ecology \& Evolution. 2016;31(5):327-9. doi:

657 10.1016/j.tree.2016.03.004. PubMed PMID: WOS:000375737200001.

658 29. Voracek M, Fisher M, Shackelford TK. Sex differences in subjective estimates of non-

659 paternity rates in Austria. Archives of Sexual Behavior. 2009;38:652-6. doi:

660 10.1007/s10508-009-9525-3. PubMed PMID: ISI:000269882800007.

66130 . Russell RJH, Wells PA. Estimating paternity confidence. Ethology and Sociobiology.

662 1987;8(3):215-20. doi: 10.1016/0162-3095(87)90045-8. PubMed PMID:

663 WOS:A1987H666700004.

664 31. Neel JV, Weiss KM. Genetic structure of a tribal population, Yanomama Indians.

665 12. Biodemographic studies.. American Journal of Physical Anthropology. 1975;42(1):25-

666 51. doi: 10.1002/ajpa.1330420105. PubMed PMID: WOS:A1975V405500004.

667 32. Alvergne A, Faurie C, Raymond M. Differential facial resemblance of young children

668 to their parents: who do children look like more? Evolution and Human Behavior.

669 2007;28(2):135-44. doi: 10.1016/j.evolhumbehav.2006.08.008. PubMed PMID:

670 ISI:000244735200008.

671 33. Alvergne A, Oda R, Faurie C, Matsumoto-Oda A, Durand V, Raymond M. Cross-

672 cultural perceptions of facial resemblance between kin. Journal of Vision. 2009;9:1-10. doi:

67323 10.1167/9.6.23. PubMed PMID: ISI:000272270500023.

674 34. Bressan P, Dal Martello MF. Talis pater, talis filius: Perceived resemblance and the

675 belief in genetic relatedness. Psychological Science. 2002;13:213-8. doi: 10.1111/1467-

676 9280.00440. PubMed PMID: ISI:000175144600003.

677 35. Daly M, Wilson MI. Whom are newborn babies said to resemble. Ethology and

678 Sociobiology. 1982;3:69-78. doi: 10.1016/0162-3095(82)90002-4. PubMed PMID:

679 ISI:A1982NX75400002.

680 36. Kaminski G, Dridi S, Graff C, Gentaz E. Human ability to detect kinship in strangers'

681 faces: effects of the degree of relatedness. Proceedings of the Royal Society B-Biological

682 Sciences. 2009;276:3193-200. doi: 10.1098/rspb.2009.0677. PubMed PMID:

683 ISI:000268276900019.

684 37. Chang L, Lu HJ, Lee LNY, Li T, Sui SS. Patrilocal Residence and Father-Child

685 Resemblance Beliefs in Relation to Paternal Investment. Parenting-Science and Practice.

686 2010;10(4):274-85. doi: 10.1080/15295192.2010.492039. PubMed PMID:

687 WOS:000284538000003.

688 38. Alvergne A, Faurie C, Raymond M. Father-offspring resemblance predicts paternal

689 investment in humans. Anim Behav. 2009;78(1):61-9. doi:

690 10.1016/J.Anbehav.2009.03.019. PubMed PMID: WOS:000267154000010.

691 39. Apicella CL, Marlowe FW. Perceived mate fidelity and paternal resemblance predict

692 men's investment in children. Evolution and Human Behavior. 2004;25:371-8. doi:

693 10.1016/j.evolhumbehav.2004.06.003. PubMed PMID: ISI:000225275300002.

694 40. Platek SM, Burch RL, Panyavin IS, Wasserman BH, Gallup GG. Reactions to children's

695 faces - resemblance affects males more than females. Evolution and Human Behavior.

696 2002;23:159-66. doi: 10.1016/S1090-5138(01)00094-0. PubMed PMID:

697 ISI:000175654500001. 
698 41. Burch RL, Gallup GG. Perceptions of paternal resemblance predict family violence.

699 Evolution and Human Behavior. 2000;21:429-35. doi: 10.1016/S1090-5138(00)00056-8.

700 PubMed PMID: ISI:000166070100004.

701 42. Alexandre GC, Nadanovsky P, Wilson M, Daly M, Moraes CL, Reichenheirn M. Cues of 702 paternal uncertainty and father to child physical abuse as reported by mothers in Rio de

703 Janeiro, Brazil. Child Abuse \& Neglect. 2011;35(8):567-73. doi:

704 10.1016/j.chiabu.2011.04.001. PubMed PMID: WOS:000295114500001.

705 43. Trivers RL. The Folly of Fools: The Logic of Deceit and Self-Deception in Human Life:

706 Basic Books; 2011.

707 44. Bressan P, Dal Pos S. Fathers See Stronger Family Resemblances than Non-Fathers

708 in Unrelated Children's Faces. Archives of Sexual Behavior. 2012;41(6):1423-30. doi:

709 10.1007/s10508-012-9983-x. PubMed PMID: WOS:000311360600015.

710 45. McLain DK, Setters D, Moulton MP, Pratt AE. Ascription of resemblance of newborns

711 by parents and nonrelatives. Evolution and Human Behavior. 2000;21:11-23. doi:

712 10.1016/S1090-5138(99)00029-X PubMed PMID: ISI:000086377400002.

713 46. Regalski JM, Gaulin SJC. Whom are Mexican infants said to resemble - monitoring

714 and fostering paternal confidence in the Yucatan Ethology and Sociobiology.

715 1993;14(2):97-113. doi: 10.1016/0162-3095(93)90010-f. PubMed PMID:

716 WOS:A1993LM13600003.

717 47. McLain DK, Setters D, Moulton MP, Pratt AE. Ascription of resemblance of newborns

718 by parents and nonrelatives. Evolution and Human Behavior. 2000;21(1):11-23. doi:

719 http://dx.doi.org/10.1016/S1090-5138(99)00029-X.

720 48. Perry G, Daly M. A model explaining the matrilateral bias in alloparental investment.

721 Proceedings of the National Academy of Sciences of the United States of America.

722 2017;114(35):9290-5. doi: 10.1073/pnas.1705910114. PubMed PMID:

723 WOS:000408536000035.

724 49. Nakagawa S. A farewell to Bonferroni: the problems of low statistical power and

725 publication bias. Behavioral Ecology. 2004;15(6):1044-5. doi: 10.1093/beheco/arh107.

726 PubMed PMID: WOS:000224482000022.

727 50. Ioannidis J. The proposal to lower $\mathrm{p}$ value thresholds to .005. JAMA. 2018;319:1429

728 - 30. doi: 10.1001/jama.2018.1536.

729 51. Heijkoop M, Dubas JS, van Aken MAG. Parent-child resemblance and kin investment:

730 Physical resemblance or personality similarity? European Journal of Developmental

731 Psychology. 2009;6:64-9. doi: 10.1080/17405620802642306. PubMed PMID:

732 ISI:000264848200007.

733 52. Schlee J, Kirchengast S. Differential grandparental investment - the impact of

734 phenotypic resemblance. Anthropologischer Anzeiger. 2015;72(4):411-25. doi:

735 10.1127/anthranz/2015/0523. PubMed PMID: WOS:000366344300003.

736 53. Oda R, Matsumoto-Oda A, Kurashima O. Effects of belief in genetic relatedness on

737 resemblance judgements by Japanese raters. Evolution and Human Behavior. 2005;26:441-

738 50. doi: 10.1016/j.evolhumbehav.2005.04.002. PubMed PMID: ISI:000231607700007.

739 54. Fisktjønmo GL. Paternal uncertainty and resemblance reporting on children among

740 brothers and sisters [Master, UiT The Arctic University of Norway] 2017.

741 55. Alvergne A, Faurie C, Raymond M. Father-offspring resemblance predicts paternal

742 investment in humans. Animal Behaviour. 2009;78:61-9. doi:

743 10.1016/j.anbehav.2009.03.019. PubMed PMID: ISI:000267154000010. 
744 56. Pashos A, McBurney DH. Kin relationships and the caregiving biases of

745 grandparents, aunts, and uncles - A two-generational questionnaire study. Human Nature-

746 an Interdisciplinary Biosocial Perspective. 2008;19(3):311-30. doi: 10.1007/s12110-008-

747 9046-0. PubMed PMID: WOS:000258530000008.

748 57. Antfolk J, Karlsson LC, Soderlund J, Szala A. Willingness to Invest in Children:

749 Psychological Kinship Estimates and Emotional Closeness. Evolutionary Psychology.

750 2017;15(2). doi: 10.1177/1474704917705730. PubMed PMID: WOS:000400358800001.

751 58. Pashos A, Schwarz S, Bjorklund DF. Kin Investment by Step-Grandparents-More

752 Than Expected. Evolutionary Psychology. 2016;14(1). doi: 10.1177/1474704916631213.

753 PubMed PMID: WOS:000373380000005.

754 59. Gray PB, Brogdon E. Do Step- and Biological Grandparents Show Differences in

755 Investment and Emotional Closeness With Their Grandchildren? Evolutionary Psychology.

756 2017;15(1). doi: 10.1177/1474704917694367. PubMed PMID: WOS:000394688300013.

757 60. Pashos A. Asymmetric Caregiving by Grandparents, Aunts, and Uncles and the

758 Theories of Kin Selection and Paternity Certainty: How Does Evolution Explain Human

759 Behavior Toward Close Relatives? Cross-Cultural Research. 2017;51(3):263-84. doi:

760 10.1177/1069397117697671. PubMed PMID: WOS:000403180300003.

761 61. McBurney DH, Simon J, Gaulin SJC, Geliebter A. Matrilateral biases in the investment

762 of aunts and uncles - Replication in a population presumed to have high paternity certainty.

763 Human Nature-an Interdisciplinary Biosocial Perspective. 2002;13(3):391-402. doi:

764 10.1007/s12110-002-1022-5. PubMed PMID: WOS:000178215300005.

765 62. Tanskanen AO. Intergenerational relations before and after offspring arrive: A

766 within-person investigation. Soc Sci Res. 2017;67:138-46. doi:

767 10.1016/j.ssresearch.2017.08.001. PubMed PMID: WOS:000411538600010.

768 63. Danielsbacka M, Tanskanen AO, Rotkirch A. The "kinship penalty": parenthood and

769 in-law conflict in contemporary Finland. Evolutionary Psychological Science. 2017. doi:

770 http://dx.doi.org/10.1007/s40806-017-0114-8.

771 64. Sherlip D, Stricker G. Expectant granparent's relationship with the middle

772 generation and their grandchildren. 106th annual confvention of the American

773 Psycological Association; San Francisco, CA.1998.

774 65. Euler HA, Hoier S, Rohde P. Relationship-specific intergenerational family ties: An

775 evolutionary approach to the structure of cultural transmission. In: Schönpflug U, editor.

776 Cultural Transmission: Psycological, developmental, social, and methodological aspects.

777 New York, NY.: Cambridge University Press; 2009. p. 70-91.

778 66. Fingermann KL. The Role of Offspring and In-Laws in Grandparents' Ties to Their

779 Grandchildren. Journal of Family Issues. 2004;25(8):1026-49. doi:

$780 \quad 10.1177 / 0192513 X 04265941$.

781 67. Lee E, Spitze G, Logan JR. Social Support to Parents-in-Law: The Interplay of Gender

782 and Kin Hierarchies. Journal of Marriage and Family. 2003;65(2):396-403. doi:

783 10.1111/j.1741-3737.2003.00396.x.

784 68. Archer J, Coyne SM. An integrated review of indirect, relational, and social

785 aggression. Pers Soc Psychol Rev. 2005;9(3):212-30. doi: 10.1207/s15327957pspr0903_2.

786 PubMed PMID: WOS:000230780500002.

787 69. Card NA, Stucky BD, Sawalani GM, Little TD. Direct and indirect aggression during

788 childhood and adolescence: a meta-analytic review of gender differences, intercorrelations, 
789

790

791

792

793

794

795

796

797

798

799

800

801

802

803

804

805

806

807

808

809

810

811

812

813

814

815

816

817

818

819

820

821

822

823

824

825

and relations to maladjustment. Child Dev. 2008;79(5):1185-229. Epub 2008/10/02. doi: 10.1111/j.1467-8624.2008.01184.x. PubMed PMID: 18826521.

70. Lahdenpera M, Gillespie DOS, Lummaa V, Russell AF. Severe intergenerational reproductive conflict and the evolution of menopause. Ecology Letters. 2012;15(11):128390. doi: 10.1111/j.1461-0248.2012.01851.x. PubMed PMID: WOS:000309395800009. 71. Cant MA, Johnstone RA. Reproductive conflict and the separation of reproductive generations in humans. Proceedings of the National Academy of Sciences of the United States of America. 2008;105(14):5332-6. doi: 10.1073/pnas.0711911105. PubMed PMID: WOS:000254893600011.

72. Hammel EA, Gullickson A. Kinship structures and survival: Maternal mortality on the Croatian-Bosnian border 1750-1898. Population Studies-a Journal of Demography. 2004;58(2):145-59. doi: 10.1080/0032472042000213703. PubMed PMID: WOS:000222477700001.

73. Pettay JE, Lahdenpera M, Rotkirch A, Lummaa V. Costly reproductive competition between co-resident females in humans. Behavioral Ecology. 2016;27(6):1601-8. doi: 10.1093/beheco/arw088.

74. Mace R, Alvergne A. Female reproductive competition within families in rural Gambia. Proceedings of the Royal Society B-Biological Sciences. 2012;279(1736):2219-27. doi: 10.1098/rspb.2011.2424. PubMed PMID: WOS:000303149800019.

75. Sear R. Kin and child survival in rural Malawi - Are matrilineal kin always beneficial in a matrilineal society? Human Nature-an Interdisciplinary Biosocial Perspective. 2008;19(3):277-93. doi: 10.1007/s12110-008-9042-4. PubMed PMID: WOS:000258530000005.

76. Willfuhr KP, Johow J, Voland E. When the mother-in-law is just as good-Differential mortality of reproductive females by family network composition. Plos One. 2018;13(3). doi: 10.1371/journal.pone.0193252. PubMed PMID: WOS:000426363200033.

77. Ji T, Wu JJ, He QQ, Xu JJ, Mace R, Tao Y. Reproductive competition between females in the matrilineal Mosuo of southwestern China. Philosophical Transactions of the Royal Society B-Biological Sciences. 2013;368(1631). doi: 10.1098/rstb.2013.0081. PubMed PMID: WOS:000331227400010. 


\section{Figure legends}

827

828 Figure 1.

829 Bar plot showing the number of grandparents reporting if their daughter, their son, or both had 830 ever made comments to them about their own children resembling them.

831

832 Figure 2.

833 Bar plot showing whom the grandparents felt most frequently or intensely argued resemblance

834 between grandparent and their child when reporting that both son and daughter had talked about 835 resemblance.

836

837 Figure 3: The number of males and females reporting whose children resemble grandmother 838 (respondent's mother) most; own children or the children of a sibling of the opposite sex (i.e., 839 males comparing their children to a sister's children, and females comparing their children to a 840 brother's children, Chi-square $=5.11, \mathrm{p}=0.024, \mathrm{n}=19$ males and $\mathrm{n}=25$ females). 


\section{Figure 1}

Comments about resemblance

Bar plot showing the number of grandparents reporting if their daughter, their son, or both had ever made comments to them about their own children resembling them. 


\section{Comments about resemblance}

25

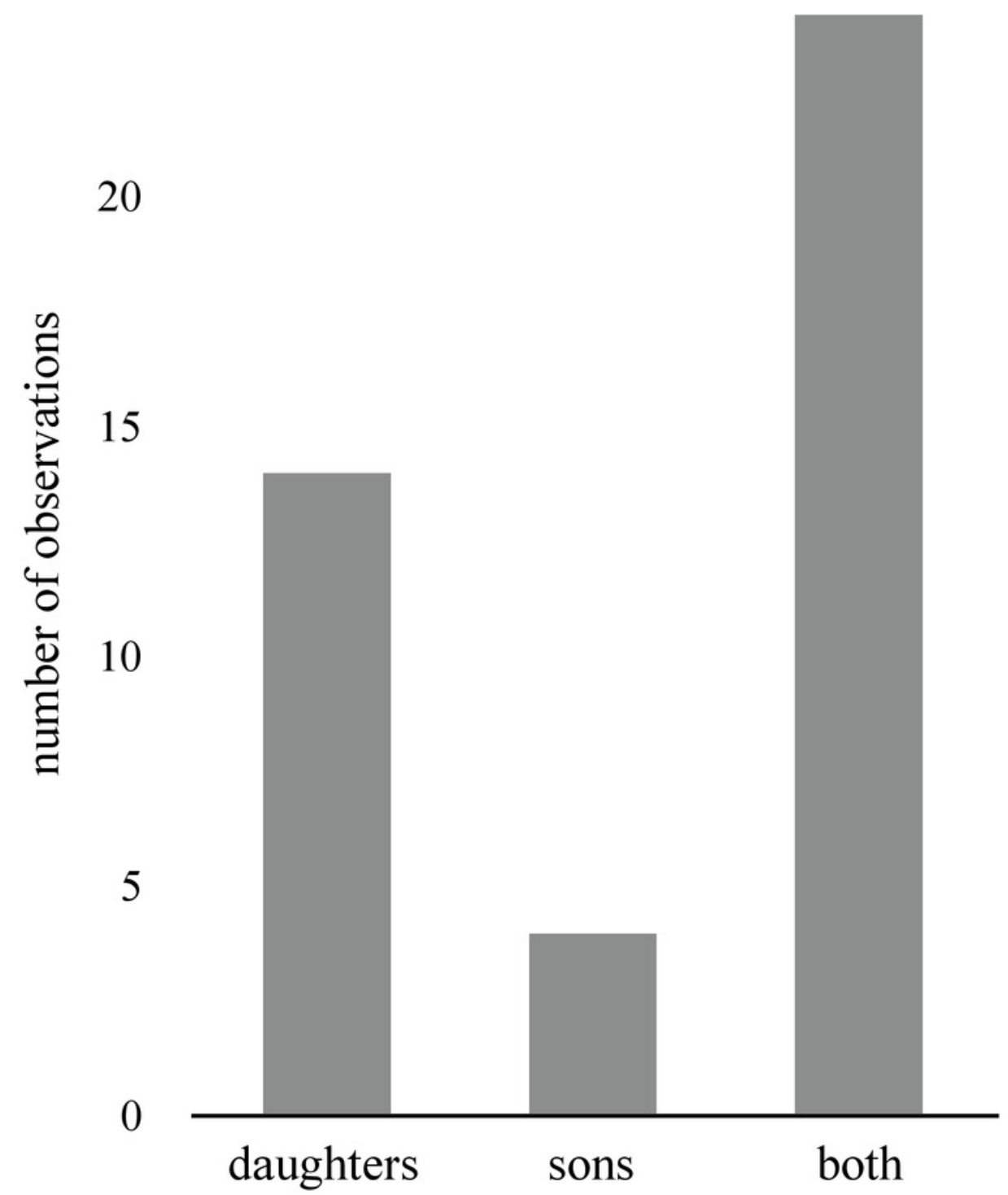




\section{Figure 2}

Strongest opinion on resemblance

Bar plot showing whom the grandparents felt most frequently or intensely argued resemblance between grandparent and their child when reporting that both son and daughter had talked about resemblance. 


\section{Strongest opinion on resemblance}

14

12

10

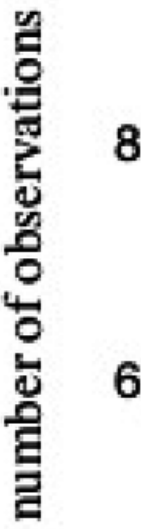

4

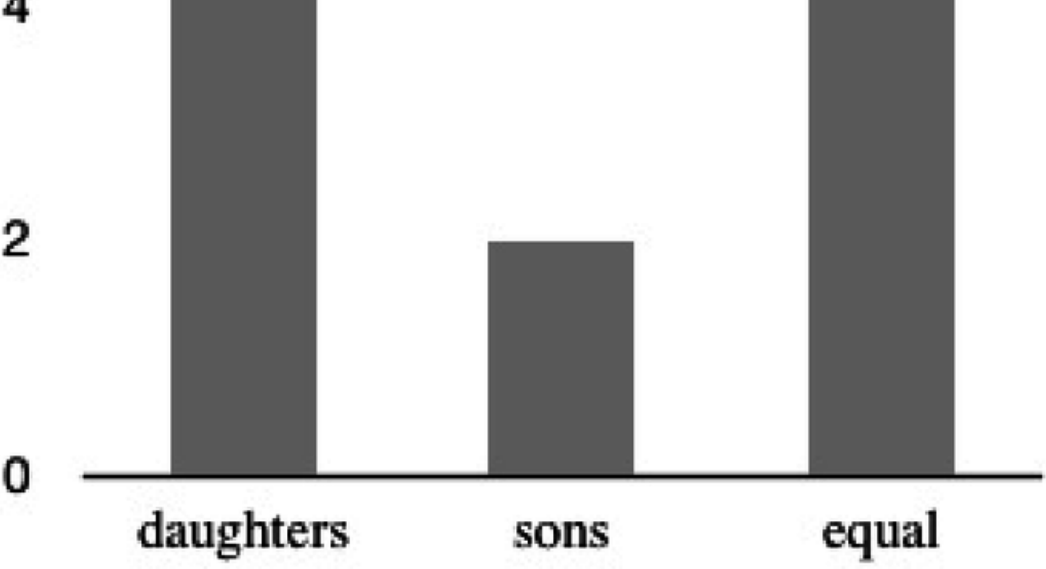




\section{Figure 3}

Who's grandchildren resemble grandmother

The number of males and females reporting whose children resemble grandmother (respondent's mother) most; own children or the children of a sibling of the opposite sex (i.e., males comparing their children to a sister's children, and females comparing their children to a brother's children, Chi-square $=5.11, p=0.024, n=19$ males and $n=25$ females). 
Who's grandchildren resemble grandmother

20

15

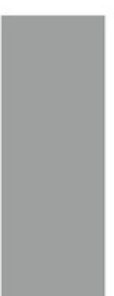

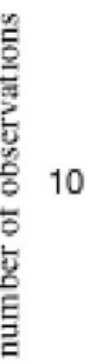

5

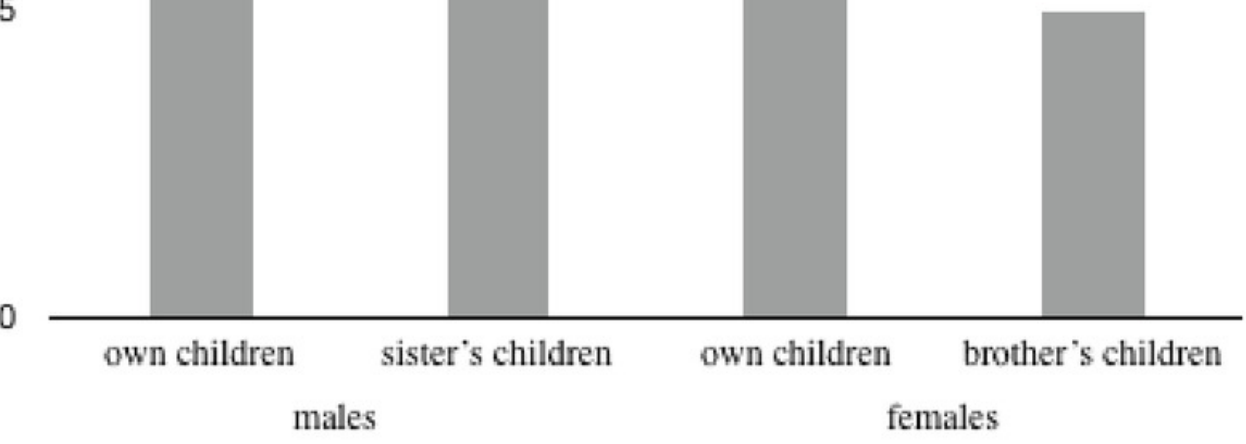

